\title{
Factors for Maintenance Priority in Malaysian University
}

\author{
Alan Chong Kim Wing, Abdul Hakim Mohammed*, Mat Naim Abdullah \\ Department of Real Estate, Universiti Teknologi Malaysia, 81310 UTM Johor Bahru, Johor, Malaysia
}

*Corresponding author: abdhakim@utm.my

\begin{abstract}
Proper maintenance planning is required to ensure the upkeep for buildings. However, maintenance of university buildings are often plague with challenges such as poor maintenance, increasing maintenance backlogs and insufficiency of budget allocation. Thus, maintenance prioritisation is practiced as part of the solution to these challenges. The purpose of this paper is to provide an overview of issues and factors related to maintenance prioritisation through literature review. It discusses the issues faced by maintenance manager in deciding priorities for maintenance work. The consideration for factors when deciding maintenance priorities is also presented in this paper. While there are a lot factors listed in previous literatures, this paper attempts to provide a general guideline for the factors that are considered in setting maintenance priorities. These factors are organisation's objective, risk, performance measurement, resources, and stakeholders. By following and incorporating these factors in deciding priorities, a maintenance programme can be designed to achieve better maintenance planning in universities.
\end{abstract}

Keywords: Maintenance planning; maintenance priority; university

(C) 2016 Penerbit UTM Press. All rights reserved

\subsection{INTRODUCTION}

In order to maintain the upkeep of buildings and its functionality, a maintenance programme which includes maintenance, repair and renovation must be designed to meet the challenges and needs of the organisation. As buildings and infrastructures ages, repair or refurbishment is required to ensure maintenance at an acceptable level. However, it is impossible to replace or rebuild every single building in an area. Thus, maintenance is crucial in making sure the asset is functional. This ensures the needs of the current users are met while preparing for future demands of the assets. While maintenance is important, its expenditure will unavoidably increase over time. This is due to the ever increasing cost for building maintenance (El haram, 1992). This is reflected in the case of Malaysian public universities in which an increase of $80 \%$ in maintenance cost can be observed in Malaysian public universities in the last five years (Lateef et al., 2010).

Building maintenance in universities were only assigned $1 \%$ from the total allocation of the entire education sector in the government budget (Lateef et al., 2010). This amount is insufficient to satisfy the required allocation for maintenance (Lateef et al., 2010 and Zul-Atif Ismail, 2014) and thus impedes the progress towards a good maintenance management. The lack of financial allocation has caused the inability to conduct maintenance management in the organisation (Zul-Atif Ismail, 2014, Ali Shah, 2009). However, even the increase in maintenance allocation will not guarantee the increase of building performance, satisfaction and maintenance itself (Lateef et al., 2010 and Pitt, 1997).

For public entities such as public universities, their funding are subjected to government intervention. Request for additional funding has to be applied and it could take months or years before being approved (Lateef, 2009). Thus, making most maintenance to be corrective or at best condition based. More than often, the budget approved is less than needed (Pitt, 1997). This often leads to budgetary cuts. One of the most common area to suffer budgetary cuts is maintenance of buildings. Certain maintenance works are deferred in order to reduce cost or give way to areas that the organisation deems to be more important. This solution is not cost-effective and maybe not be the best practice to achieve value for money (Lateef, 2009). However, the reality is that the allocation for maintenance will never match the required amount and thus prioritisation is practiced. Maintenance prioritisation is a way to tackle the problem of lack in maintenance allocation (Shen and Spedding, 1998).

This paper presents the issues and factors involved with maintenance prioritisation through literature reviews. A number of methods, frameworks and models were reviewed from the literatures from the period of 1990 to 2015. The review is based on various sources such as books and databases (Scopus, Emerald, Taylor and Francis).

\subsection{PRIORITY MANAGEMENT}

According to (Roy, 1994), priority management is the "allocation of resources, or the expression of preference, to specific order or order groupings (whether supplies, production, or customer orders), in response to current pressures on operational productivity and/or customer 
service, with the aim of relieving those pressures while at the same time promoting, or minimizing the deleterious impact upon, the wider economic and strategic goals of the company". Priority management is applicable to asset or building maintenance as it has been carried out in hospital, office buildings and public buildings (Lateef, 2009, Ali and Hegazy, 2014, Au-Yong et al., 2014 and Yusof, 2012).

The concept of priority is widely seen in decision making. Multi-criteria methodology is often used to prioritise task and it is usually based on weighing the rating of relevant criteria. The variables for priority management can be described as a relationship of cause and effect (Roy, 1994). Any changes in the relationship will result in instability which then stimulates prioritising actions. The required corrective actions are directly proportionate to instability. The relationship can be a loop as bad decisions in prioritising will lead to greater instability which require more interventions (Roy, 1994).

\subsection{ISSUES IN MAINTENANCE PRIORITISATION}

An action plan has meaning only in reference to available resources (budget, delay, etc). With limited resources for facilities upgrading (maintenance, renovation, rehabilitation), the question would than be, which buildings or facilities should be prioritised, and how much should be invested at what level (Rosenfeld and Shohet, 1999).

However, maintenance prioritisation is a challenging task for maintenance manager (Shen and Spedding, 1998). This is due to maintenance plan usually requires the establishment of priorities among maintenance actions based on conflicting management objectives (Hassanain et al., 2003). This in turn causes maintenance manager to face difficulty in setting priorities as there are a number of factors to be considered in the process. This is common as qualitative assessment requires deliberation of multiple subjective elements that might not have standard solutions. The consequences of poor prioritisation can cause inadequate allocation to maintenance work especially strategic works (Shen et al., 1998). This is also confirmed by Yusof et al. 2012 and Yang et al. 2006 which stated that decision on maintenance priority carried out with subjective evaluation based on experience and knowledge of the maintenance coordinator may lead to poor resource allocation.

Another issue is that maintenance problem is often reduced to a comparison between actions' costs and the available budget without consideration for the pertinence and consequences of the actions (Taillandier et al., 2011). The strategies will be void of true maintenance decision when it has been reduced to this state of cost conscious only. Thus, having the right priorities will influence deferred maintenance either positively or negatively. (Chew et al., 2004) stated that maintenance faces conflicting objectives due to one side trying to ensure optimum economic value for building while the other side tries to reduce the expenditure cost as much as possible. This indicates that most organisations are only willing to reach the minimum requirements in maintenance in order to save cost. This would cause ineffectiveness and inefficiency in maintenance performance as the maximum potential has not been realized. The dilemma in this situation is that the efforts to maximize this maintenance performance is limited by economic considerations as no organisation has unlimited budget. Thus, prioritisation is practiced to juggle between the required works and the available budget.

For Malaysian higher education institution, maintenance priority is based on corporate image (Lateef, 2011). All other maintenance works in other than those related to administration and academic buildings are deferred when faced with limited budget. This is due to Malaysian university practices maintenance prioritisation by judging which buildings are important to the organisation's goal. This rule of thumb is easy to understand and accepted by decision makers. However, maintenance planning involves multiple factors while planning according to "rule of thumb" will not be sufficient. The priorities should not only be on corporate image. At the same time, it must not focus just on availability of budget and the immediate needs.

As such, there is a need to investigate how maintenance should be prioritised with limited resources being allocated to achieve best value for money (Shen et al., 1998 and Flores-Colen et al., 2010).

\subsection{FACTORS FOR MAINTENANCE PRIORITY}

Before establishing maintenance priority, it is important to understand the factors which affects the setting of priorities in the maintenance plan. According to (Bernard Williams Associates, 1994), the factors involved are dynamic as there are always different situation, perspective and preferences during the process of setting maintenance priorities. By considering the various factors involved in setting priorities, setbacks from bad decisions can be avoided. Based on previous literatures, these factors are organisation objective and goal, performance measurement, risk, resources, and stakeholders. These factors are presented in the following section.

\section{Organisational Objective and Goal}

In any organisation, maintenance should be designed to align with the organisation's goals and objectives. This is done through the organisational policies which dictates the maintenance planning process (Lavy, 2014). By establishing objectives, performance measurement and maintenance prioritisation related activities can be justified (Zul-Atif Ismail, 2014). Goals of strategic level are the first step in planning a maintenance. This can be seen in a model by (Wordsworth and Lee, 2001) with organisational policies leading the maintenance decision-making process. The objective area refers to the decision on the usage of an infrastructure asset in order to accomplish its goal.

However, objectives are often taken for granted and often neglected. These objectives are usually not explicitly addressed but implicitly embraced (Schraven et al., 2011). The asset management process models may not have written policies especially on the objectives (Schraven et al., 2011). The objectives are assumed to have existed and often replaced by performance thresholds, resource allocation and project selection.

Organisation goal and objectives can influence maintenance in various ways such as competitive advantages and better maintenance managements (Parida et al., 2015) However, objectives can conflict with each other and requires prioritisation among them (Schraven et al., 2011). Conflicting objectives imposes different needs and requirements on maintenance works depending on involved parties. A compromise between objectives is required in order to sort out the conflict to ensure optimality of maintenance. In (Bertolini and 
Bevilacqua, 2006), priorities were set using Goal Programming to select a maintenance policy for oil refinery plants. The method used by (Bertolini and Bevilacqua, 2006) is able to handle multiple conflicting goals for problems related to fund allocation, location allocation, and information system project evaluation. Through this, a maintenance policy which is a compromise of conflicting goals was proposed.

\section{Risk}

Risk is one of the frequently used factors in deciding maintenance planning. Risk is related to safety and the avoidance of accident is one of the main purpose of effective maintenance (Arunraj and Maiti, 2010). Risk is critical because it affects the degree of risk of life, physical integrity, health and comfort (Flores-Colen et al., 2010). In risk assessment, risk is usually defined by its likelihood and consequences (Leveson, 2015 and Hastak and Baim, 2010). Likelihood refers to the possibility of the risk occurring while consequences refers to the required expenditure in terms of equipment, material, labor cost, to restore a system (Rogers, 2013).

A few methods to assess risk for maintenance are proposed in the literatures. Analytical Hierarchy Process and Goal Programming was used in determining the maintenance policy based on risk of equipment failure and cost of maintenance (Arunraj and Maiti, 2010). (Rogers, 2013) presented a risk assessment technique to develop maintenance programmes based on risk profile of facility managers. Another frequently used assessment is risk using failure mode and effect analysis (FMEA) such as FMEA using failure and consequences as criteria (Tarek et al., 2010), risk associated with failure modes using predictive maintenance data (frequency severity and possibility of detection (Vijay Kumar and Chaturvedi, 2011). In (Flores-Colen et al., 2010), risk is measured based on its effects of the building, effects on the users, criticality of the area and reliability of the diagnosis during inspection. In another study by (Shen et al., 1998), criteria such as the effects on users and effects on fabrics are used in maintenance prioritisation for public buildings.

\section{Performance Measurement}

Performance measurement is often used as an indicator for maintenance prioritisation. No action should be taken without first understanding and measuring the performance of the assets. According to (Kennerley and Neelym, 2003), organisations that measure their performance performs better than those that did not. In decision making for a maintenance plan, measurement for performance and conditions are required to understand the situation of the assets and its alignment with organisation's objective (Schraven et al., 2011, Parida et al., 2015 and Neumann and Markow, 2004 ).

There are a lot of performance measurement models and method as stated in literatures. The common and widely used approaches for performance measurement includes benchmarking, balanced scorecard, post-occupancy evaluation (POE), key performance indicators and critical success factors (Lavy, 2014). Historical maintenance data are often used as inputs in measuring performance as well (Ali and Hegazy, 2014). Computerized maintenance management systems are often used to keep track of maintenance data and monitor maintenance works.

In a case study of hospital by (Ali and Hegazy, 2014), the performance assessment used four KPIs namely condition, level of service, sustainability and risk. The condition observes the physical deterioration while level of service observes how well the component serves the users. Sustainability involves the assessment of effect on the environment such as energy saving and waste while risk focuses on failure probability and consequences. In another study by (Flores-Colen et al., 2010), the physical performance of a building facade was assessed in building age, external environment and. It is notable that assessment of physical condition, building status, effects on fabrics, service provision and users are often used to prioritise maintenance works (Shen et al., 1998).

\section{Resources}

Resources refer to the means necessary to realize actions. The common reference to this is budget. In any maintenance planning, budget is one of the dominant determinant (Ali Shah, 2009, Flores-Colen et al., 2010 and Rogers, 2013). An action plan is only feasible in reference to available resources -equipment, labor, time, cost (Taillandier et al., 2011 and Rogers, 2013). One of the reasons for changes and prioritisation to a maintenance plan is due to limited budget (Ali Shah, 2009). Without sufficient resources, maintenance work can not be executed efficiently. In a study by (Flores-Colen et al., 2010), cost can be divided into cost of maintenance, cost related to recurrent problems, cost of non-functioning, cost of temporary accesses and cost of non maintenance.

In another study by (Antti and Mats, 2011), cost is divided into direct and indirect cost. Direct costs consist of labor costs, spare parts, and other cost directly linked to the maintenance works while indirect cost consist of cost from recovering for lost of production and insufficient quality. Furthermore, the author proposed that cost of conformance is associated with cost for preventive maintenance and cost of non conformance with cost for corrective maintenance.

\section{Stakeholders}

Because of multi-functionality of an asset, multiple actors (users, political bodies, private sector organisation) affect the decision on the maintenance plan. Their expectations and request need to be managed as there might be conflicting interests among them (Ali Shah, 2009 and Schraven et al., 2011). When prioritising maintenance work, their decisions and feedbacks will impact not only the assets, but also themselves as the stakeholders. For example, public universities receives funding from the government and plans out the maintenance plan. Then the works are outsourced to private parties. The completed works are then utilized by the members of the university. Each stakeholder has a relationship with each other and all of them has their own expectations.

In turn, users expectation are considered as one of the factors in determining maintenance planning. User's satisfaction towards the building performance is vital and needs to be taken into consideration. Inefficient maintenance works creates complaints and building managers can investigate the source of problems from these complaint data (Lateef et al., 2010 and Ali Shah, 2009). 


\subsection{DISCUSSION}

In a comprehensive maintenance management, there are three levels which are the strategic, tactical and operational level (Crespo Marquez and Gupta, 2006). The strategic level transforms the business priorities into maintenance priorities through long term planning while the tactical enables these plans through short term planning. The operational level acts as a linkage between strategic and tactical planning while carrying out the needed works (Crespo Marquez and Gupta, 2006).

In practice, maintenance personnel prefer to evaluate maintenance priorities using technical and tangible methods such as condition, risk and cost assessment (Ali and Hegazy, 2014 and Flores-Colen et al., 2010 ). These evaluation methods focused on the operational and tactical levels. However, maintenance priorities should take into consideration of factors such as stakeholders' expectation and goal and objectives to reflect the strategic level of maintenance planning. Strategic factors should not be neglected as it is reflects the core business of the organisation. It is difficult for the maintenance managers to grasp the importance of these strategic factors when considering maintenance priorities as they appear as intangible compared to operational and tactical factors (Umar, 2011). The ideal situation in deciding priorities should be based on the balance between the completion of maintenance works and the strategic goals of the organisation. The factors listed in this paper can act as a general guideline for maintenance manager for the prioritisation practices. All factors should be considered before deciding on priorities as to enable maintenance manager to make well-informed and rational decisions on which work to be prioritised and deferred. The outcome of these decision should also be aligned with the strategic needs of the organisation in order to truly achieve a comprehensive maintenance plan.

\subsection{CONCLUSION}

The study attempts to highlight the issues and factors related to maintenance prioritisation for university buildings. While there are a lot of process models and methods to accomplish this, the consideration such as the factors which establish the maintenance priority remains vague. Through literature reviews, five major factors have been identified which are organisation objective, risk, performance, resources, and stakeholders. The limitation for this study is that some factors such as political, aesthetic and others factors are not mentioned as the paper focuses on factors that are frequently mentioned in the literatures.

The integration of strategic, tactical and operational factors into the maintenance prioritisation practice enables maintenance manager to be aligned with the organisation's goal while ensuring maintenance works are carried out properly. There are still little understanding in the relationship among these factors and its effect on maintenance priority. A good understanding of these factors can improve the maintenance plan and thus reducing maintenance backlog for an organisation. For future research, it is suggested that in-depth studies on the relationships of these factors and the design of prioritising methods which includes these factors to be carried out.

\section{Acknowledgement}

The authors would like to express their sincere appreciation and gratitude to Universiti Teknologi Malaysia in supporting this study.

\section{References}

El haram. (1992). Physics Based Vision: Principles and Practice, COLOR. Boston: Jones and Bartlett.

Lateef, O. A., Khamidi, M. F., and Idrus, A. (2010). Building Maintenance Management In A Malaysian University Campus: A Case Study, Australasian Journal of Construction Economics and Building, 10(1/2), 76-89.

Zul-Atif Ismail. (2014). Improving Maintenance Management Practices for Building Facility. KICEM Journal of Construction Engineering and Project Management, 4(3), 21-32

Lateef, O. A., Khamidi, M.F., and Idrus, A. (2011). Appraisal of the Building Maintenance Management Practices of Malaysian Universities. Journal Build Appraisal, 6(3-4), 261-275.

Ali Shah, A. (2009). Cost Decision Making in Building Maintenance Practice in Malaysia. Journal of Facilities Management, 7(4), $298-306$.

Pitt, T.J. (1997). Data Requirements for the Prioritisation of Predictive Building Maintenance. Facilities, 15(3/4), 97-104.

Lateef, O. A. (2009). Case for Alternative Approach to Building Maintenance Management of Public Universities. Journal of Building Appraisal, 5(3), 201-212.

Shen, Q., and Spedding, A. (1998). Priority Setting in Planned Maintenance: Practical Issues in Using the Multi-Attribute Approach. Building Research and Information, 26(3), 169-180.

Roy, W. (1994). Priority Management: New Theory for Operations Management. International Journal of Operations and Production Management, 14(6), 4-24.

Ali, A., and Hegazy, T. (2014). Multicriteria Assessment and Prioritisation of Hospital Renewal Needs. Journal of Performance of Constructed Facilities, 28(3), 528538.

Au-Yong, C., Ali, A., and Ahmad, F. (2014). Significant Characteristics of Scheduled and Condition-Based Maintenance in Office Buildings. Journal of Performance of Constructed Facilities, 28(2), 257-263.

Yusof, N., Abdullah, S., Zubedy, S., and Najib, N. U. M. (2012). Residents' Maintenance Priorities Preference: The Case of Public Housing in Malaysia. ProcediaSocial and Behavioral Sciences, 62, 508-513.

Rosenfeld, Y., and Shohet, I. M. (1999). Decision Support Model for Semi-automated Selection of Renovation Alternatives. Automation in Construction, 8(4), 503510.

Hassanain, M., Froese, T., and Vanier, D. (2003). Framework Model for Asset Maintenance Management.. Journal of Performance of Constructed Facilities, 17(1), 51-64.

Shen, Q., Lo, K., and Wang, Q. (1998). Priority Setting in Maintenance Management: A Modified Multi-Attribute Approach Using Analytic Hierarchy Process. Construction Management and Economics, 16(6), 693-702.

Yang, Z., Chang, Q., Djurdjanovic, D., Ni, J., and Lee, J. (2006). Maintenance Priority Assignment Utilizing On-line Production Information. Journal of Manufacturing Science and Engineering, 129(2), 435-446.

Taillandier, F., Sauce, G., and Bonetto, R. (2011). Method and Tools for Building Maintenance Plan Arbitration. Engineering, Construction and Architectural Management, 18(4): 343-362.

Chew. M. Y. L., Tan, S. S., and Kang, K. H. (2004). Building Maintainability- Review of State of the Art. Journal of Architectural Engineering, 10(3), 80-87. 
Flores-Colen, I., de Brito, J., and Freitas, V. (2010). Discussion of Criteria for Prioritisation of Predictive Maintenance of Building Facades: Survey of 30 Expers. Journal of Performance of Constructed Facilities, 24(4), 337-344.

Bernard Williams Associates. (1994). Facilities Economics: Incorporating Premises Audits. Building Economic Bureau, Shortlands, U.K.

Lavy, S., Garcia, J. A., Scinto, P., and Dixit, M. K. (2014). Key Performance Indicators for Facility Performance Assessment: Simulation of Core Indicators Construction Management and Economics, 32(12), 1183-1204.

Wordsworth, P., and Lee, R. (2001). Lee's Building Maintenance Management. London: Blackwell Science.

Schraven, D., Hartmann, A., and Dewulf, G. (2011). Effectiveness of Infrastructure Asset Management: Challenges for Public Agencies. Built Environment Project and Asset Management, 1(1), 61-74.

Parida, A., Kumar, U., Galar, D., and Stenstrom, C. (2015). Performance Measurement and Management for Maintenance: A Literature Review. Journal of Quality in Maintenance Engineering, 21(1), 2-33.

Bertolini, M., and Bevilacqua, M. (2006). A Combined Goal Programming- AHP Approach to Maintenance Selection Problem. Reliability Engineering and System Safety, 91(7), 839-848.

Arunraj, N. S., and Maiti, J. (2010). Risk-based Maintenance Policy Selection Using AHP and Goal Programming. Safety Science, 48(2), 238-247.

Leveson,N. (2015). A Systematic Approach to Risk Management Through Leading Safety Indicators. Reliability Engineering and System Safety, $136,17-34$.

Hastak, M., and Baim, E. (2010). Risk Factors Affecting Management and Maintenance Cost of Urban Infrastructure. Journal of Infrastructure Systems, 7(2), 67-75.

Rogers, J. W. (2013). Can Facility Manager Impact the Expected Budgetary Outcomes of Robust Asset Management Programs?. Facilities, 31(1/2), 56-67.

Tarek, H., Shipra Singh, A., and Mohamed, A. (2010). Two Condition Indicators for Building Components Based on Reactive-Maintenance Data. Journal of Facilities Management, 8(1), 64-74.

Vijay Kumar, E., and Chaturvedi., S. K. (2011). Prioritisation of Maintenance Task on Industrial Equipment for Reliability. International Journal of Quality and Reliability Management, 28(1), 109-126

Kennerley, M., and Neelym A. (2003). Measuring Performance in a Changing Business Environment. International Journal of Operations and Production Management, 23(2), 213-229.

Neumann, L. A., and Markow, M. J. (2004). Performance-Based Planning and Asset Management. Public Works Management and Policy, 8(3), 156-161.

Antti, S., and Mats, D. (2011). Cost of Poor Maintenance. Journal of Quality in Maintenance Engineering, 17(1), 63-73.

Crespo Marquez, A., and Gupta, J. N. D. (2006). Contemporary Maintenance Management: Process, Framework and Supporting Pillars. Omega, 34(3), 313-326.

Umar, A. (2011). A Framework for Strategic Planning in Maintenance. Journal of Quality in Maintenance Engineering, 17(2), 150-162. 